\title{
Clinical outcome of the off-pump coronary artery bypass surgery- a comparison between combined high thoracic epidural anaesthesia with GA and GA alone
}

\author{
Saiful Islam Azad ${ }^{1 *}$, Abdul Khaleque Beg${ }^{2}$, A. Y. F. Elahi Chowdhury ${ }^{3}$, U. H. Shahera Khatun ${ }^{4}$ \\ ${ }^{1}$ Assistant Registrar, ${ }^{2}$ Professor and Head, ${ }^{3}$ Ex. Professor and Head, Dept. of Anaesthesiology,NICVD, Dhaka, ${ }^{4}$ Professor \\ and Head, Dept.of Anaesthesiology and ICU, DMCH, Dhaka, Bangladesh.
}

*Corresponding author: E-mail: saifulazad@yahoo.com

\begin{abstract}
:
Background: The common challenges for the cardiac anaesthesiologist during off pump coronary artery surgery $(O P C A B)$ include haemodynamic stability during the different stressful surgical events and multiple cardiac manipulations, providing adequate myocardial protection, and obtaining effective postoperative analgesia leading to early discharge from the intensive care unit.

Objective: This study has been undertaken with a view to find out whether a combined high thoracic epidural anaesthesia (HTEA) with general anaesthesia (GA) is safe and more efficient in providing overall cardiovascular stability as well as improving the parameters leading to a better outcome in terms of a shorter and more predictable road maps to recovery.

Methods: Sixty patients aged within 40-70 years, without having any coagulopathy disorder, any emergency surgery or left main disease scheduled for CABG on beating heart were enrolled in prospective, randomized observational comparative study. Patients were divided in two groups. In group A patients received GA alone and in group B patients received high thoracic epidural anaesthesia with $G A$. The parameters including heart rate, SPO2, CVP, arterial blood pressure, ECG, and ABG analysis were recorded before induction, during induction, intubation and during different events of the surgery. Post operative pain score, sedation score, ventilator hour, duration in the ICU stay, rescue analgesic need and post operative complications was assessed and recorded.

Results: significant per-operative mean heart rate changes were observed all the events except at wound closure and during anastomosis with D1 / D2 and the mean difference of mean arterial pressure at intubations, skin incision, sternotomy, pericardiotomy, during anastomosis of distal end of the graft with RCA, PDA, $L C X$ and D1/D2 were observed statistically significant $(p<0.05)$. No incidence of different arrhythmia occurred in group $B$, premature ventricular complex $(P V C)$ was statistically significant $(p<0.05)$ between two groups. No significant change was found in per-operative $\mathrm{pH}$ of arterial blood, $\mathrm{PaCO}_{2}$ and $\mathrm{PaO}_{2}$ changes at different times. Post operative pain score (VAS 0-100) in different time interval was found significant $(p<0.05)$ change between two groups in all follow-up times. Status of rescue analgesics were observed statistically significant $(p<0.05)$. The mean ventilator hours were $7.4 \pm 1.09$ hours in group $A$ and $5.3 \pm 0.81$

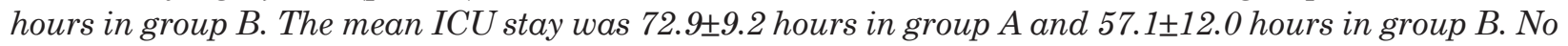
post-operative complication was observed in both groups. The data were compiled and analyzed by using statistical software SPSS (ver. 12.0) and significance test performed by unpaired t test and Chi square test. $P$ value $<0.05$ was considered as statistically significant.

Conclusion: Both anaesthetic techniques are equally safe but better clinical outcome of the OPCAB surgery with the high thoracic epidural anaesthesia with GA.
\end{abstract}

Keywords: HTEA, GA, OPCAB

(Journal of BSA, 2009; 22(2): 54-60)

\section{Introduction:}

General anaesthesia is the most commonly used anaesthetic technique and considered the "gold standard" for coronary artery by-pass grafting
(CABG) performing either on pump or off pump ${ }^{1}$.During general anaesthesia in cardiothoracic surgery neurohumoral response is an important problem for patients who is augmented 
by various painful surgical interventions $s^{2,3}$ and haemodynamic changes during endotracheal intubation may be detrimental in patients with coronary artery diseases due to concomitant increase in myocardial oxygen demand, decrease in oxygen supply, and the possibility of myocardial ischaemia ${ }^{4-6}$. In the postoperative period inadequate analgesia may increase morbidity by causing adverse haemodynamic, metabolic, immunologic and haemostatic attentions ${ }^{7-10}$. This is often difficult to achieve optimal pain relief.During beating-heart surgery, to obtain an adequate exposure of the anastomosis site with restrained cardiac motion; and to protect the myocardium from ischaemia during coronary artery flow interruption the anaesthetist must be prepared to handle severe haemodynamic alterations, transient deterioration of cardiac pump function, and acute intraoperative myocardial ischaemia. Within the past few years, high thoracic epidural anaesthesia (HTEA) as an adjunct to general anaesthesia (GA) has become more prevalent ${ }^{1,11}$ and has been shown to be potentially beneficial in patients with coronary diseases. Thoracic epidural anaesthesia provides good protection from stress response ${ }^{12,13}$, ensures hemodynamic stability ${ }^{12,14}$, allows early extubation ${ }^{15}$, improves distribution of coronary blood flow and reduce demand for oxygen ${ }^{16}$. Awake CABG is associated with a certain amount of undeniable psychological stress and therefore requires excellent patients' compliance. There may be significant hemodynamic compromise due to Trendelenburg position and luxation of the heart during revascularization of the circumflex artery so circumflex artery disease represents an exclusion criterion for this anaesthetic technique. In addition, because the anaesthetic level does not extend to the lower limbs, TEA alone is limited to complete arterial revascularization ${ }^{1}$. So combination of high thoracic epidural anaesthesia and general anaesthesia will provide better intraoperative and postoperative better outcome in off pump CABG surgery than general anaesthesia alone. In the previous studies in different countries, various benefits have been reported in combining thoracic epidural anaesthesia with general anaesthesia during cardiac surgery. The statistical risk of epidural haematoma following TEA as between 1 : 150,000 and 1: 1500(95\% confidence) and up to 1: $1000(99 \% \text { confidence })^{17}$.In this study we have tried to evaluate the clinical outcome of the OPCAB surgery including the above mentioned limitations of the previous related studies with the anaesthetic technique combined high thoracic epidural anaesthesia with GA.

This study has been undertaken with a view to find out whether a combined HTEA with GA is safe and more efficient.

\section{Materials And Methods:}

Sixty patients aged between 40-70 years, ASA I, II, III \& IV and NYHA - I, II, III \& IV scheduled for OPCAB were included in this study and divided into two groups, thirty in each group and were randomly selected. Group A patients received GA alone and group $\mathrm{B}$ patients received high thoracic epidural anaesthesia with GA. Patients were excluded if they had left main disease, history of previous cardiac surgery, left ventricular ejection fraction $<35 \%$ ,contraindications of regional anaesthesia and emergency surgery. After selection of the patients, grouping, entry of name of the patient in the case record form and the written informed consent was taken from all patients on the preoperative day. Premedication with oral midazolam $7.5 \mathrm{mg}$ was given in the night before surgery. Patients were fasted six hours before operation.After transferring the patients into the operation room, standard monitoring (five lead ECG, pulse oxymetry) was instituted. All patients were pre-oxygenated with $100 \%$ oxygen. With all aseptic precaution intravenous cannulation, radial arterial catheterization and central venous catheterization was established. Epidural catheter was inserted at the level of T1-2 or T2-3 interspaces in the patients of group B . Fifteen minutes before surgery, high thoracic epidural anaesthesia was given in group B patients with $0.25 \%$ bupivacaine $10 \mathrm{ml}$ bolus followed by $8 \mathrm{ml} / \mathrm{hr}$ through continuous epidural infusion during operative period and general anaesthesia was induced in all patients of both group with fentanyl $10 \mu \mathrm{g} / \mathrm{kg}$ IV , propofol $1 \mathrm{mg} / \mathrm{kg}$ IV .Tracheal intubations were facilitated by pancuronium bromide $0.1 \mathrm{mg} / \mathrm{kg}$ and anaesthesia was maintained with propofol infusion $50-100 \mu \mathrm{g} / \mathrm{kg} / \mathrm{min}$, fentanyl infusion $1-2 \mu \mathrm{g} / \mathrm{kg} / \mathrm{hr}$, oxygen $35 \%$ and air $65 \%$. The parameters including heart rate, SPO2, CVP , arterial blood pressure, , arrhythmia in ECG, and ABG analysis were recorded before induction, during induction, intubation and during different events 
of the surgery ( skin incision, sternotomy, pericardiotomy, coronary artery anastomosis with graft, sternum closure and wound closure). At the end of the surgery, all patients were transferred to the intensive care unit without extubation and ventilation was maintained by the ventilator. When there were accepted criteria for tracheal extubation ,patients were extubated and shifted to the post operative care unit after accepted criteria for discharge from intensive care unit. Post operative analgesia was performed by Ketorolac $30 \mathrm{mg}$ IV every eight hourly for all patients but in group B , in addition to this , thoracic epidural infusion $0.25 \%$ bupivacaine $3-4 \mathrm{ml} / \mathrm{hr}$ up to 48 hours was given also. If need rescue analgesics was given. Post operative pain score, sedation score, postoperative ventilator hour, duration in the ICU stay, rescue analgesic need, and post operative complications (respiratory, neurological, and epidural haematoma) was assessed and recorded. The data were compiled and analyzed by using statistical software SPSS (ver. 12.0) and significance test performed by unpaired t test and Chi square test. P value $<0.05$ was considered as statistically significant, $\mathrm{P}<0.01$ highly significant .

\section{Results:}

Table I

Anthrometric characteristic of the study patients $n s=$ Not significant

\begin{tabular}{lccc}
\hline & $\begin{array}{c}\text { Group A } \\
(\mathrm{n}=30) \\
\text { Mean } \pm \text { SD }\end{array}$ & $\begin{array}{c}\text { Group B } \\
(\mathrm{n}=30)\end{array}$ & $\begin{array}{c}\mathrm{p} \\
\text { Mean } \pm \text { SD }\end{array}$ \\
\hline Age (years) & $49.9 \pm 7.1$ & $49.3 \pm 7.2$ & $0.789^{\mathrm{ns}}$ \\
Weight $(\mathrm{kg})$ & $62.3 \pm 7.4$ & $62.1 \pm 9.9$ & $0.934^{\mathrm{ns}}$ \\
Height $(\mathrm{cm})$ & $151.4 \pm 5.5$ & $148.9 \pm 15.7$ & $0.490^{\mathrm{ns}}$ \\
BSA $\left(\mathrm{m}^{2}\right)$ & $1.6 \pm 0.11$ & $1.7 \pm 0.15$ & $0.410^{\mathrm{ns}}$ \\
\hline
\end{tabular}

No significant mean age, weight, height and body surface area (BSA) differences were found between two groups (Table I).

Table II

Changes in heart rate during study period

\begin{tabular}{lccc}
\hline & $\begin{array}{c}\text { Group A (n=30) } \\
\text { Mean } \pm \text { SD }\end{array}$ & $\begin{array}{c}\text { Group B (n=30) } \\
\text { Mean } \pm \text { SD }\end{array}$ & $\begin{array}{c}\text { p } \\
\text { value }\end{array}$ \\
\hline Pre-op value & $79.3 \pm 7.5$ & $77.2 \pm 13.8$ & $0.538^{\mathrm{ns}}$ \\
Induction & $83.2 \pm 14.1$ & $72.2 \pm 11.1$ & 0.007 \\
Intubation & $93.3 \pm 11.8$ & $75.3 \pm 11.9$ & 0.001 \\
Skin incision & $88.3 \pm 13.7$ & $74.2 \pm 11.3$ & 0.001 \\
Sternotomy & $92.3 \pm 11.7$ & $76.2 \pm 12.4$ & 0.001 \\
Pericardiotomy & $86.9 \pm 14.9$ & $78.0 \pm 11.6$ & 0.028 \\
Sternum closure & $96.9 \pm 13.5$ & $85.6 \pm 13.4$ & 0.007 \\
Wound closure & $94.3 \pm 13.7$ & $86.9 \pm 13.5$ & $0.075^{\mathrm{ns}}$ \\
During anastomosis of distal end of the graft with & & & \\
$\quad$ & $92.5 \pm 14.5$ & $81.3 \pm 10.4$ & 0.004 \\
$\quad$ LAD $\quad 103.6 \pm 17.7$ & $90.6 \pm 7.4$ & 0.018 \\
$\quad$ PDA & $104.8 \pm 18.7$ & $86.4 \pm 9.1$ & 0.016 \\
$\quad$ LCX & $110.3 \pm 11.0$ & $67.0 \pm 6.5$ & 0.001 \\
$\quad$ D1/D2 & $98.6 \pm 13.5$ & $93.6 \pm 17.8$ & 0.229 ns \\
$\quad$ OM1/ OM2/ OM3 & $78.4 \pm 13.4$ & $87.2 \pm 12.7$ & 0.011 \\
During anastomosis of proximal end of the & $98.7 \pm 18.7$ & $87.4 \pm 13.9$ & 0.023 \\
graft with the aorta & & & \\
\hline
\end{tabular}

The mean heart rate changes at wound closure and during anastomosis with diagonal (D1/D2) were not statistically significant ( $p>0.05)$ in unpaired t-test and others were statistically significant $(p<0.05)$ (Table II). 


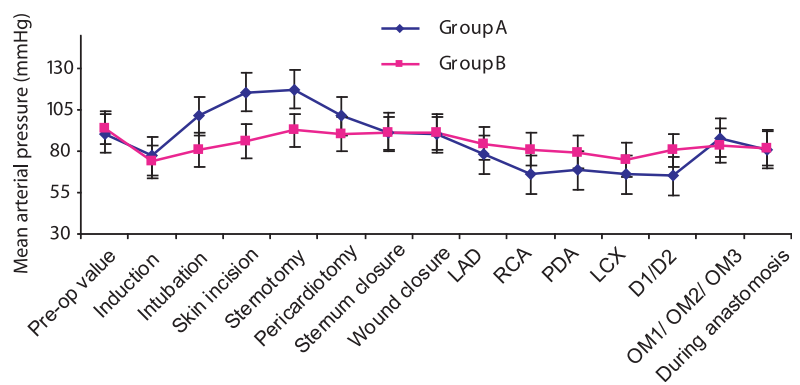

Fig.-1: Line diagram showing mean arterial pressure $(\mathrm{mmHg})$ changes.

The mean of mean arterial pressure changes at intubation, skin incision, sternotomy, pericardiotomy, during anastomosis of distal end of the graft with RCA, PDA, LCX and D1/D2 were statistically significant and others were not statistically significant ( Figure 1).

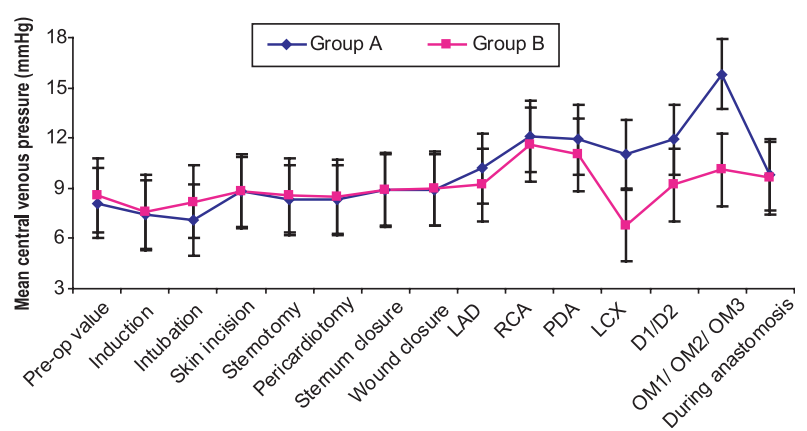

Fig.-2: Line diagram showing central venous pressure changes .

The mean central venous pressure changes during anastomosis of distal end of the graft with PDA, LCX, D1/D2 and OM1/OM2/OM3 were statistically significant and others were not statistically significant (Figure 2).

Table III

Per-operative different arrhythmia $(n=60)$

\begin{tabular}{lccccc}
\hline & \multicolumn{2}{c}{$\begin{array}{c}\text { Group A } \\
(\mathrm{n}=30)\end{array}$} & \multicolumn{2}{c}{$\begin{array}{c}\text { Group B } \\
(\mathrm{n}=30)\end{array}$} & $\begin{array}{c}\mathrm{p} \\
\text { value }\end{array}$ \\
& $\mathrm{n}$ & \multicolumn{1}{c}{$\%$} & $\mathrm{n}$ & $\%$ & \\
\hline Ventricular tachycardia & 3 & 10.0 & 0 & 0.0 & $0.118^{\mathrm{NS}}$ \\
Ventricular fibrillation & 1 & 3.3 & 0 & 0.0 & $0.500^{\mathrm{NS}}$ \\
Premature Ventricular complex (PVC) & 9 & 30.0 & 0 & 0.0 & 0.001 \\
Atrial fibrillation & 0 & 0.0 & 0 & 0.0 & - \\
Supra ventricular tachycardia & 3 & 10.0 & 0 & 0.0 & $0.118^{\mathrm{NS}}$ \\
\hline
\end{tabular}

No incidence of different arrhythmia occurred in group B. Premature ventricular complex was statistically significant between two groups but other arrhythmia was not statistically significant (Table III).

Table IV

PH of arterial blood changes at different times. $n s=$ Not significant

\begin{tabular}{lccc}
\hline & $\begin{array}{c}\text { Group A } \\
(\mathrm{n}=30)\end{array}$ & $\begin{array}{c}\text { Group B } \\
(\mathrm{n}=30)\end{array}$ & $\begin{array}{c}\mathrm{p} \\
\text { value }\end{array}$ \\
& Mean $\pm \mathrm{SD}$ & Mean $\pm \mathrm{SD}$ & \\
\hline Pre-op value & $7.41 \pm 0.02$ & $7.42 \pm 0.05$ & $0.238^{\mathrm{ns}}$ \\
Intubation & $7.46 \pm 0.04$ & $7.44 \pm 0.02$ & $0.555^{\mathrm{ns}}$ \\
Sternotomy & $7.39 \pm 0.06$ & $7.43 \pm 0.04$ & $0.190^{\mathrm{ns}}$ \\
Pericardiotomy & $7.42 \pm 0.03$ & $7.43 \pm 0.04$ & $0.280^{\mathrm{ns}}$ \\
Sternum closure & $7.39 \pm 0.04$ & $7.42 \pm 0.02$ & $0.107^{\mathrm{ns}}$ \\
Wound closure & $7.40 \pm 0.05$ & $7.42 \pm 0.04$ & $0.196^{\mathrm{ns}}$ \\
\hline
\end{tabular}

$\mathrm{PH}$ of arterial blood changes between two groups within normal range in both groups (Table IV).

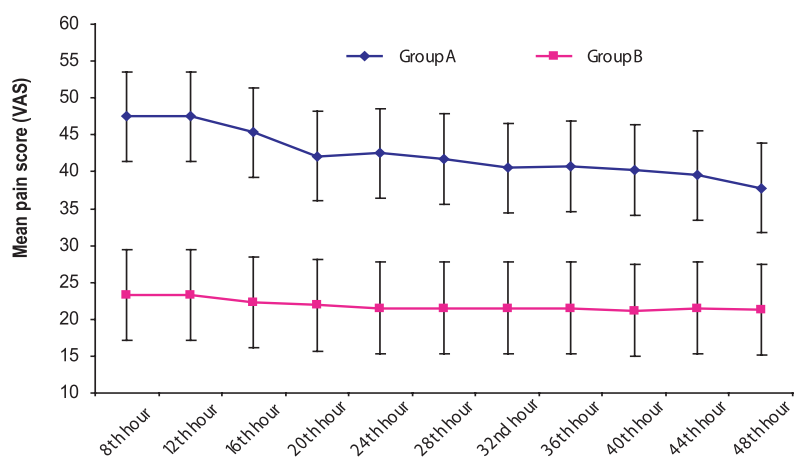

Fig.-3: Line diagram showing Post operative pain score(VAS; 0-100) of the patients after extubation. 
The post operative pain score (VAS; 0-100) after extubation in different time interval found significant $(p<0.05)$ change between two groups in all follow-up times (Fig.-3).

\section{Table V}

Mean distribution of post operative sedation score at first six hour

\begin{tabular}{lccc}
\hline $\begin{array}{l}\text { One hour } \\
\text { interval }\end{array}$ & $\begin{array}{c}\text { Group A } \\
(\mathrm{n}=30) \\
\text { Mean } \pm \text { SD }\end{array}$ & $\begin{array}{c}\text { Group B } \\
(\mathrm{n}=30) \\
\text { Mean } \pm \text { SD }\end{array}$ & $\begin{array}{c}\mathrm{p} \\
\text { value }\end{array}$ \\
\hline $1^{\text {st }}$ hour & $2.9 \pm 0.3$ & $2.8 \pm 0.5$ & $0.352^{\text {ns }}$ \\
$2^{\text {nd }}$ hour & $2.8 \pm 0.5$ & $2.1 \pm 0.6$ & 0.001 \\
$3^{\text {rd }}$ hour & $2.4 \pm 0.7$ & $1.4 \pm 0.5$ & 0.001 \\
$4^{\text {th }}$ hour & $2.1 \pm 0.5$ & $1.1 \pm 0.3$ & 0.001 \\
$5^{\text {th }}$ hour & $1.4 \pm 0.5$ & $1.0 \pm 0.0$ & - \\
$6^{\text {th }}$ hour & $1.15 \pm 0.4$ & $1.0 \pm 0.0$ & - \\
\hline
\end{tabular}

The mean distribution of post operative sedation score at first six hour were significant change between two groups except 1st hour, which was not significant (Table V).

Table VI

Status of rescue analgesics received by the patients

\begin{tabular}{lccccc}
\hline Rescue & \multicolumn{2}{c}{$\begin{array}{c}\text { Group A } \\
\text { analgesics }\end{array}$} & \multicolumn{2}{c}{ Group B } & $\mathrm{p}$ \\
& $\mathrm{n}=30)$ & \multicolumn{2}{c}{$(\mathrm{n}=30)$} & value \\
& $\mathrm{n}$ & $\%$ & $\mathrm{n}$ & $\%$ & \\
\hline Received & 16 & 53.3 & 6 & 20.0 & 0.015 \\
Not received & 14 & 46.7 & 24 & 80.0 & \\
\hline
\end{tabular}

The status of rescue analgesics received was statistically significant in chi square test (Table VI).

\section{Table VII}

Mean ventilator hour and duration of ICU stay

\begin{tabular}{lccc}
\hline & $\begin{array}{c}\text { Group A } \\
(\mathrm{n}=30) \\
\end{array}$ & $\begin{array}{c}\text { Group B } \\
(\mathrm{n}=30)\end{array}$ & $\begin{array}{c}\mathrm{p} \\
\text { value }\end{array}$ \\
& Mean $\pm \mathrm{SD}$ & Mean $\pm \mathrm{SD}$ & \\
\hline Ventilator hour & $7.4 \pm 1.09$ & $5.3 \pm 0.81$ & 0.001 \\
ICU stay & $72.9 \pm 9.2$ & $57.1 \pm 12.0$ & 0.001 \\
\hline
\end{tabular}

The difference of the mean postoperative ventilator hour and duration of ICU stay were statistically significant (Table VII).

\section{Discussion:}

In the present study the mean age, weight, height and body surface area of the patients were similar in both groups but were higher in different studies than the present study. The higher range of the different studies may be due to increased life expectancy in their country.In the current study the male patients was predominant, which is consistent with Kessler et al. ${ }^{1}$, Salvi et al. ${ }^{20}$ and Scott et al. ${ }^{19}$ studies. In this study it was observed that per-operative mean heart rate changes at wound closure and during anastomosis of distal end of the graft with D1/D2 were not statistically significant $(p>0.05)$, however rest of others times were significantly $(\mathrm{p}<0.05)$ less in group $B$, which is comparable with Kundu et al., Kessler et al., and Salvi et al. Studies ${ }^{18,1,20}$. It was found in this current study that per-operative mean of mean arterial pressure (MAP) changes at intubation, skin incision, sternotomy, pericardiotomy were significantly $(\mathrm{p}<0.05)$ higher in group A but during anastomosis of distal end of the graft with RCA, PDA, LCX and D1/D2 were ignificantly $(\mathrm{p}<0.05)$ higher in group B and others were almost similar between two groups. Kessler et al. ${ }^{1}$ obtained consistent findings in their study in group $\mathrm{B}$, which is similar with the present study, however in group A the present study found higher with the above study findings before anastomosis but during anastomosis of distal end of the graft with different coronary artery mean of MAP were decline below $70 \mathrm{mmHg}$. Similarly, Salvi et al. ${ }^{20}$ reported identical finding in this regard, which is closely support the present study. In this study it was observed that per-operative mean CVP changes at during anastomosis of distal end of the graft with PDA, LCX, D1/D2 and OM1/OM2/OM3 were significantly $(\mathrm{p}<0.05)$ higher in group A and others were almost consistent between two groups. On the other hand Kessler et al. (2005) ${ }^{1}$ and Salvi et al. (2004) ${ }^{20}$ have observed identical mean CVP of their patients, which are closely resemble with the present study.

In this study it was found that per-operative arrhythmia ventricular tachycardia (VT) $10.0 \%$ in group A but none was found in group B which is similar with Kundu et al. ${ }^{18}$ study. Arrhythmia ventricular fibrillation (VF) was $3.3 \%$ in group A and none was found in group $\mathrm{B}$, which closely resembles with Bakhtiary et al. Study ${ }^{21}$. Arrhythmia premature ventricular contraction 
(PVC) was $30.0 \%$ in group $\mathrm{A}$ and none was found in group B, which also support Bakhtiary et al. Study $^{21}$, where they observed $27.3 \%$ and $6.1 \%$ in group A and group B respectively and Kundu et al. ${ }^{18}$ study observed $40.0 \%$ and $10.0 \%$. Arrhythmia atrial fibrillation (AF) not occurred in both group in the present study, however Kundu et al. ${ }^{18}$ observed in this study $10.0 \%$ in group A. Bakhtiary et al. ${ }^{18}$ reported $27.3 \%$ in group $\mathrm{A}$ and $6.1 \%$ in group B, which differ with the present study, this may be due to left main disease was excluded and GA was given with TIVA in the presents study.

In the present study, per-operative $\mathrm{pH}$ of arterial blood was changed within normal limit in both groups and per-operative $\mathrm{PaCO}_{2}, \mathrm{PaO}_{2}$ changes at different times had no significant $(p>0.05)$ change between two groups which support Kessler et al. study $^{1}$.Kessler et al. ${ }^{1}$ have assessed the VAS (0$100 \mathrm{~mm}$ ) were subsequently higher in group A than group $B$ at all times after surgery, always reaching significance level except at 48 hours. Similarly Salvi et al. ${ }^{20}$ assessed the VAS $(0-10 \mathrm{~mm})$ for the first 24 hour period were 0.9 at rest and 1.7 during coughing in each patients the VAS score always less than $<2$, which indicating that the post-operative pain relief was excellent in their study patients (group B). In the present study it was found that post operative pain score VAS $(0-100 \mathrm{~mm})$ was $>40$ in group $A$ and $<30$ in group B after extubation which was significantly $(\mathrm{p}<0.05)$ higher in group $\mathrm{A}$ at all the different follow-up times. The results obtained in the present study are comparable with the above studies. In the present study post operative sedation score at first hour was almost similar between two group, however the remaining times sedation score were significantly $(\mathrm{p}<0.05)$ higher in group A. Kessler et al. ${ }^{1}$ reported that sedation score were significantly higher at 6 hour post operatively in group A. In the current series it was observed that the status of rescues analgesics need 53.3\% in group $\mathrm{A}$ and $20.0 \%$ group $\mathrm{B}$ and the difference was statistically significant $(p<0.05)$. In this study no post-operative complication was found between two groups. In a study Scott ${ }^{19}$ done a study on 202 patients in group A and 206 in group B and found the incidence of postoperative confusion was $5.5 \%$ and $1.5 \%$ in group $\mathrm{A}$ and group $\mathrm{B}$ respectively. The incidence of CVA was $3.0 \%$ in group $A$ and $1.0 \%$ in group B. In this study it was found that the mean ventilation hours was significantly $(p<0.05)$ higher in group A, which were $7.4 \pm 1.09$ in group A and $5.3 \pm 0.81$ hours in group B. Similarly, the mean ICU stay was also significantly $(\mathrm{p}<0.05)$ higher in group A, which were $72.9 \pm 9.2$ hours in group A and $57.1 \pm 12.0$ hours in group B. Kessler et al. ${ }^{1}$ observed the higher mean ventilation hours in group $\mathrm{A}$, which was 5.0 \pm 2.6 hour in group $\mathrm{A}$ and $3.7 \pm 2.4$ hours in group B. The mean ICU stay was also higher in group A, which was $11.2 \pm 7.9$ hours and 9.2 \pm 8.1 hours in group B. Salvi et al. ${ }^{26}$ observed the mean ventilation hour was $4.6 \pm 2.9$ in group B and the mean ICU stay was $36.0 \pm 19.2$ hours.

\section{Conclusion:}

Based on the present study results, both anaesthetic techniques were equally safe. However, HTEA with GA appeared to be more safe and efficient.

\section{References}

1. P. Kessler, T. Aybek, Gerd Neidhart, Selami Dogan, Volker Lischke, Dorothee H Bremerich, et al., Comparison of three anesthetic techniques for Off-pump coronary artery bypass grafting: general anaesthesia, Combined general and high thoracic epidural anaesthesia, or high thoracic epidural anaesthesia alone. Journal of Cardiothoracic and Vascular Anaesthesia 2005;19: 32-39.

2. Didem Dal ,Meral Kanbak ,Meltem Caglar ,Ulku Aypar. A background infusion of morphine does not enhance postoperative analgesia after cardiac surgery.Can J Anesth 2003; 50(5): 476-479.

3. Wolman RL. Patient controlled analgesia following thoracic surgery. In: Gravlee a Rauk (Eds). Pain management in cardiothoracic surgery. Philadelphia: Lippincort company ;1993; 59-87.

4. Stoelting RK. Circulatory changes during ditrect laryngoscopy and tracheal intubation. Influence of duration of laryngoscopy with or without prior lidocaine. Anaesthesiology 1977;47: 381-3.

5. Ebert JP, Pearson JD, Gelman s, Harris C, Bradley EL. Circulatory responses to laryngoscopy: the comparative effects of placebo, fentanyl and esmolol.Can J. Anesth 1989; 36: 301-6.

6. Stone DJ, Gal TJ. Airway management. In: Miller Rd (Ed.) Anaesthesia, $5^{\text {th }}$. New york; 
Churchill Livingstone Inc; 2000;1444-6.

7. Mark A. Chaney, Intrathecal and Epidural Anaesthesia and Analgesia for Cardiac Surgery.Anesth Analg 2006;102:45-64.

8. Weissman C. The metabolic response to stress: an overview and update. Anesthesiology 1990;73:308-27.

9. Kehlet H. Surgical stress: the role of pain and analgesia. Br J Anaesth 1989;63:189-95.

10. Roizen MF. Should we all have a sympathectomy at birth or at least preoper-atively. Anaesthesiology 1988;68:482-4.

11. Goertz AW, Seeling W, Heinrich H, et al., Influence of high thorasic epidural anaesthesia on left ventricular contractility assessed using the end systolic pressure length relationship.Acta Anaesthesiol Scand 1993;37:38-133.

12. Blomberg S, Curelaru I, Emanuelsson H, et al., Thoracic epidural anaesthesia in patients with unstable angina pectoris.Eur Heart $J$ 1989;10:437-44.

13. Reiz S, Nath S, Rais O, Effects of thoracic epidural block and prenalterolon coronary vascular resistance and myocardial metabolism in patients with coronary artery disease. Acta Anaesthesiol Scand 1980;24:11.135.

14. Blomberg S, Emanuelsson H, Ricksten SE, Thoracic epidural anaesthesia and central hemodynamics in patients with unstable angina pectoris.Anesthesiology 1990; 73: 840-7.

15. Kock M, Blomberg S, Emanuelsson H, et al. Thoracic epidural anaesthesia improves global and regional left ventricular function during stress induced myocardial ischemia in patients with coronary artery disease. Anesth Analg 1990;71:625-30.

16. RF Davis, LW DeBoer, PR Maroko, Thoracic epidural anaesthesia reduces myocarial infract size after coronary artery occlusion in dogs. Anaesthesia and Analgesia 1986; 965:71 1-717.

11. Goldstein Dean, SJ Kim, et al. A survey of spinal and epidural techniques in adult cardiac surgery. J Cardiothoracic Vase Anesth 2001;15:158-168.

12. JF Olivier, N.Le, et al. Comparison of the three different epidural solutions in off-pump cardiac surgery: pilot study. $\mathrm{Br} J$ Anaesth 2005;95(5):685-691.
13. Ganapathy S, Murkin JM, Dobkowski W, Boyd D. Stress and inflammatory response after beating heart surgery versus conventional bypass surgery: the role of thoracic epidural anaesthesia. Heart Surg Forum 2001;4:323-7.

14. Stenseth R, Bjella L, Berg EM, Christensen O, Levang OW, Gisvold SE. Thoracic epidural analgesia in aortocoronary bypass surgery. I: haemodynamic effects. Acta Anaesthesiol Scand 1994; 38: 826-33.

15. Joachimsson PO, Nystrom SO, Tyden H. Early extubation after coronary artery surgery in efficiently rewarmed patients: a postoperative comparison of opioid anaesthesia versus inhalation anaesthesia and thoracic epidural analgesia.J Cardiothorat Anesth 1989;3:444-54.

16. Stenseth R, Berg EM, Bjella L, Christensen O, Levang OW, Gisvold SE. Effects of thoracic epidural analgesia on coronary hemodynamics and myocardial metabolism in coronary artery bypass surgery. J Cardiothorac Vasc Anesth 1995; 9: 503-9.

17. Ho AM, Chung DC, Joynt GM. Neuroaxial blockade and hematoma in cardiac surgery: estimating the risk of a rare event that has not (yet) occurred. Chest 2000;117:551-555.

18. RK Kundu, AK Beg, S Hossain, N Haque, Mahafuddoza, A Chowdhury. Comparative study of haemodynamic status and arrhythmia between combined epidural with general anaesthesia and general anaesthesia alone in Off-pump coronary artery bypass (OPCAB) surgery. J Bangladesh Coll Phys Surg 2008;26:116-120.

19. Scott MB, Turfrey DJ, Ray DA. Aprospective randomized study of the potential benefits of thoracic epidural anaesthesia and analgesia in patients undergoing coronary artery bypass grafting. Anesth Analg 2001;93(5):28-35.

20. Salvi L, Sisillo E, Brambillasca C, Juliano G, Salis S and Marino MR. High thoracic epidural anaesthesia for off-pump coronary artery by pass surgery. J Cardiothorac Vasc Anesth 2004;18(3):256-62.

21. Bakhtiary F, Therapidis P, Dzemali O, Ak K, Ackermann H, Meininger D, Kessler P, Kleine P, Moritz A, Aybek T, and Dogan S. Impact of high thoracic epidural anaesthesia on incidence of perioperative atrial fibrillation in off-pump coronary bypass grafting: A prospective randomized study. Thorac Cardiovasc Surg 2007;134:460-4. 